\title{
Evaluating the Utility of Remotely-Sensed Soil Moisture Retrievals for Operational Agricultural Drought Monitoring
}

\author{
Submitted to "IEEE Journal of Selected Topics in Applied Earth Observations and Remote \\ Sensing"
}

\author{
John D. Bolten ${ }^{1}$, Wade T. Crow ${ }^{2}$, Xiwu Zhan ${ }^{3}$, Thomas J. Jackson ${ }^{2}$, Curt Reynolds ${ }^{4}$ \\ ${ }^{1}$ Hydrological Sciences Branch, NASA GSFC, Greenbelt, MD \\ ${ }^{2}$ USDA-ARS-HRSL, Beltsville, MD \\ ${ }^{3}$ NOAA-NESDIS, Camp Springs, MD \\ ${ }^{4}$ USDA-FAS-OGA-IPAD, Washington, DC
}

\section{Popular Summary}

The United States Department of Agriculture (USDA) International Production Assessment Division (IPAD) is responsible for forecasting and assessing global crop production and agricultural yields. IPAD uses a combination of satellite-derived data and land surface and crop modeling for these assessments, particularly in regions that lack traditional ground sensing data. From these analyses, IPAD provides a timely and standardized estimate of the status of global crop production - an essential part of international food security and management in areas and times of agricultural drought or stress. Soil moisture is a critical variable in the IPAD crop forecasting system because crop growth cycles are very dependent upon the near surface soil moisture amounts, particularly for root zone. However, soil moisture is a difficult to sample globally and at present, uncertainty in these soil moisture estimates lead to errors in crop forecasting ability and accuracy.

In this study, we have presented the results from a study evaluating a soil moisture data assimilation system designed to integrate satellite-derived soil moisture estimates into a water balance model for improved root-zone soil moisture estimates. Our analysis primarily involves the comparison of multiple soil moisture model estimates with and without the integrated satellite observations over the conterminous United States. From this analysis we can quantitatively evaluate the performance of the data assimilation system and the root-zone soil moisture estimates which will be delivered to IPAD. Our results indicate that the system provides improved root-zone soil moisture estimates over most of the US with some degradation in the northeast and semi-arid areas of the southwest, which may be the result of inappropriate model parameters or poor satellite-derived products over vegetation regions. 


\begin{abstract}
Soil moisture is a fundamental data source used by the United States Department of Agriculture (USDA) International Production Assessment Division (IPAD) to monitor crop growth stage and condition and subsequently, globally forecast agricultural yields. Currently, the USDA IPAD estimates surface and root-zone soil moisture using a two-layer modified Palmer soil moisture model forced by global precipitation and temperature measurements. However, this approach suffers from well-known errors arising from uncertainty in model forcing data and highly simplified model physics. Here we attempt to correct for these errors by designing and applying an Ensemble Kalman filter (EnKF) data assimilation system to integrate surface soil moisture retrievals from the NASA Advanced Microwave Scanning Radiometer (AMSR-E) into the USDA modified Palmer soil moisture model. An assessment of soil moisture analysis products produced from this assimilation has been completed for a five-year (2002 to 2007) period over the North American continent between $23^{\circ} \mathrm{N}-50^{\circ} \mathrm{N}$ and $128^{\circ} \mathrm{W}-65^{\circ} \mathrm{W}$. In particular, a data denial experimental approach is utilized to isolate the added utility of integrating remotelysensed soil moisture by comparing EnKF soil moisture results obtained using (relatively) lowquality precipitation products obtained from real-time satellite imagery to baseline Palmer model runs forced with higher quality rainfall. An analysis of root-zone anomalies for each model simulation suggests that the assimilation of AMSR-E surface soil moisture retrievals can add significant value to USDA root-zone predictions derived from real-time satellite precipitation products.
\end{abstract}

